Rhode Island College

Digital Commons @ RIC

\title{
Hyperphosphatemia in Hemodialysis Patients: Can an Educational Intervention Make a Difference?
}

Mofoluso Oluyemisi Agbelese

Rhode Island College

Follow this and additional works at: https://digitalcommons.ric.edu/etd

Part of the Other Nursing Commons

\section{Recommended Citation}

Agbelese, Mofoluso Oluyemisi, "Hyperphosphatemia in Hemodialysis Patients: Can an Educational Intervention Make a Difference?" (2016). Master's Theses, Dissertations, Graduate Research and Major Papers Overview. 140.

https://digitalcommons.ric.edu/etd/140

This Major Paper is brought to you for free and open access by the Master's Theses, Dissertations, Graduate Research and Major Papers at Digital Commons @ RIC. It has been accepted for inclusion in Master's Theses, Dissertations, Graduate Research and Major Papers Overview by an authorized administrator of Digital Commons @ RIC. For more information, please contact digitalcommons@ric.edu. 



\section{HYPERPHOSPHATEMIA IN HEMODIALYSIS PATIENTS: CAN AN EDUCATIONAL INTERVENTION MAKE A DIFFERENCE?}

A Major Paper Presented

by

Mofoluso Oluyemisi Agbelese

Approved:

Committee Chairperson

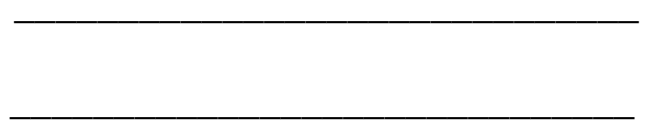

Committee Members

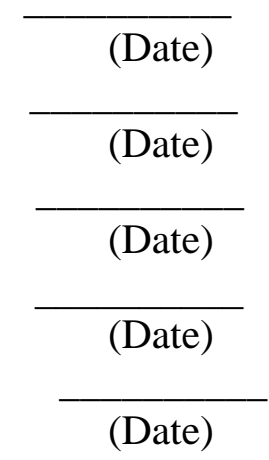

Director of Master's Program

Dean, School of Nursing

(Date) 


\title{
HYPERPHOSPHATEMIA IN HEMODIALYSIS PATIENTS: CAN AN
}

EDUCATIONAL INTERVENTION MAKE A DIFFERENCE?

\author{
By \\ Mofoluso Oluyemisi Agbelese
}

A Major Paper Submitted in Partial Fulfillment

of the Requirements for the Degree of

Master of Science in Nursing

in

The School of Nursing

Rhode Island College

2016 


\begin{abstract}
Adherence to the treatment regimen, including proper phosphate binder use and the monitoring of dietary phosphorus intake, is crucial to optimal health outcomes in hemodialysis patients. Hyperphosphatemia remains a significant health problem in hemodialysis patients since excessive serum phosphate is associated with increased morbidity and mortality rates in this patient population. Hyperphosphatemia can occur due to lack of knowledge. The purpose of this program is to determine the effect of an educational intervention on phosphorus knowledge in hemodialysis patients.

Participants consisted of a convenience sample of 12 hemodialysis patients. The teaching intervention utilized a pre and posttest design. The difference in pre and posttest scores was analyzed to determine the effect of the educational intervention on patients' knowledge of phosphorus. Post test scores revealed a statistically significant increase in phosphorus knowledge in participants $(Z$ value $=-2.97 ; p<.05)$. Responses to the openended qualitative question revealed that friends and family members were important support team members that enabled participants to adhere to their dietary phosphorus regimen. Implications for further studies include the expansion of educational interventions to include friends and family members and the inclusion of individuals from various ethnic and racial backgrounds. Nurses are strategically situated in hemodialysis units to provide patient education. Advanced practice registered nurses can provide leadership to other nurses on the use of evidenced-based educational interventions that positively impact patient outcomes.
\end{abstract}




\section{Acknowledgements}

I am grateful to my Savior Jesus Christ for seeing me through it all; I am what I am by His grace.

I would like to express my deep gratitude to my committee chair (Dr. Lynn Blanchette) for her unwavering support, insight, and feedback throughout the many twists and turns as I completed this project. I would certainly be remiss not to thank Dr. Jeanne Schwager, committee member and advisor extraordinaire for her advice, expertise and belief in me even when all seemed lost. To Dr. Cynthia Padula, I want to say thank you. Thank you for your sincere interest in my success and for making yourself available even though you were very busy.

I would like to thank Donna Lewis (Registered Renal Dietitian) and two nephrologists in the dialysis center: Dr. Susie Hu and Dr. Eric Kerns for critiquing my questionnaire and teaching materials to make sure they are useful, appropriate and valid. I am also grateful to Donna Lynch and Erica Trembath for going the extra mile to assist me in getting my project approved within the dialysis company.

I want to thank my husband Titus for his unwavering support, encouragement, understanding and prayers. I wish I could put your name on the diploma too because I am able to obtain it because you have been so supportive. I am grateful for my dear children Victoria, Christine and Sophia Joy who have sacrificed so much so I can finish my programs. Thank you for focusing on your school and for making your dad and I so proud of your accomplishments and thank you for reassuring me 'It's ok mom' when I've questioned why I am putting myself through school again. I love you all. 
A special gratitude to my parents Dr. Sophie Oluwole and the late Dr. Joseph Fapohunda who taught me the 'Yes you can' attitude decades before it became a popular slogan.

Finally, I would like to acknowledge other friends and family members not previously mentioned who have nevertheless been instrumental in my completing this program thank you all. 


\section{Table of Contents}

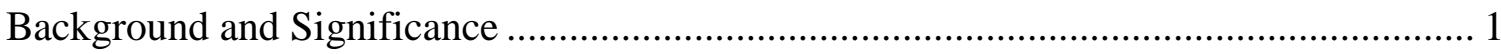

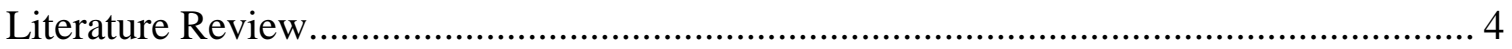

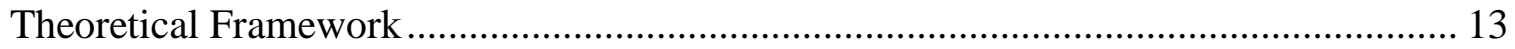

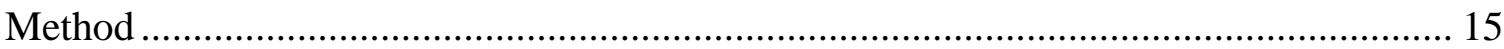

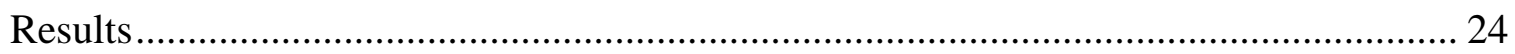

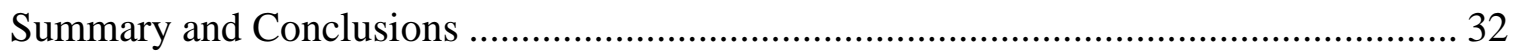

Recommendations and Implications for Advanced Nursing Practice .............................. 33

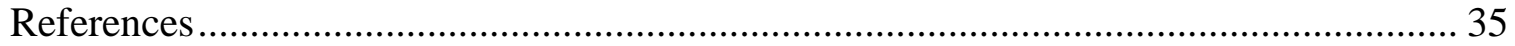

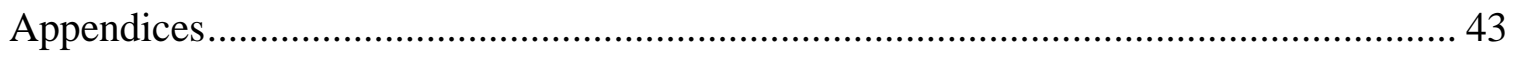


Hyperphosphatemia in Hemodialysis Patients: Can an Educational Intervention Make a Difference?

\section{Background and Significance}

Chronic kidney disease (CKD) is a growing global public health issue. In the United States (US), CKD affects an estimated 26 million people (American Society of Nephrology, 2014) and is associated with high morbidity (Sinha \& Prasad, 2014). Although hypertension and diabetes are the most common causes of CKD (Centers for Disease Control and Prevention [CDC], 2014), CKD is an independent risk factor for hypertension, stroke, and heart attack (CDC, 2014; Hruska, Choi, Memon, Davis, \& Mathew, 2010). CKD is also associated with a high mortality rate (CDC, 2014, Sinha \& Prasad, 2014). Patients with end-stage renal disease (ESRD) in stages 3 to 5 of CKD who have also had a heart attack, are 51\% more likely to die within a year as compared to $36 \%$ of heart attack patients with no history of CKD (National Kidney and Urologic Diseases Information Clearinghouse [NKUDIC], 2012). The risk of premature death is so high in CKD patients that these individuals are more likely to die than reach ESRD (CDC, 2014). CKD is also associated with high treatment cost (Sinha \& Prada, 2014). In 2009 , the estimated cost of treating patients with ESRD in the US exceeded $\$ 40$ billion (NKUDIC, 2012). In 2011, the total Medicare expenditure per year per hemodialysis (HD) patient was $\$ 87,945$ (USRD, 2013). This constitutes a significant problem since HD is the most common method of renal replacement treatment for patients in ESRD who must obtain treatment for their failed kidneys (Idier, Untas, Koleck, Chauveau \& Rascle, 2011). ESRD patients are also at increased risk of bone mineral disorders, and an 
abnormal serum phosphate level is implicated in bone mineral disorders (National Kidney Foundation [NKF], 2014).

Phosphorus is an important mineral that is necessary for maintaining strong bone and teeth and is important in other metabolic processes such as proper cell functioning (Kalantar-Zadeh et al., 2010; Nguyen \& Wang, 2012). Generally, there is no shortage of serum phosphate since phosphorus is readily available in various food sources (KalantarZadeh et al., 2010). However, in patients with CKD, serum phosphate levels can easily exceed normal levels as the kidney progressively loses its ability to excrete waste materials including excess phosphorus. Hyperphosphatemia - defined as serum phosphate of $5.5 \mathrm{mg} / \mathrm{dL}$ or greater (Lertdumrongluk et al., 2013), is therefore a common abnormality in hemodialysis patients whose kidney disease has progressed to ESRD.

Although hyperphosphatemia is linked to secondary hyperparathyroidism which in turn is associated with increased risk of cardiovascular disease (CVD), hyperphosphatemia alone has also been linked to increased risk of CVD in hemodialysis patients (Gonzalez-Parra, Tuñón, Egido, Ortiz, A., 2012; Cupisti et al., 2012). While CVD presents a significant health burden on the general population as the $4^{\text {th }}$ leading cause of mortality (American Heart Association, 2014), CVD presents a disproportionately greater burden on hemodialysis patients because CVD is the main cause of death in this group of patients (Abe, Okada \& Soma, 2013; Mizobuchi, Towler \& Slatopolsky, 2009). Obtaining and maintaining the serum phosphate level within recommended parameters is therefore vital in the treatment of ESRD patients on hemodialysis. Since the kidneys have lost their ability to successfully filter out excess phosphorus, HD patients depend on other means of controlling serum phosphate: 1) 
removal of serum phosphate during dialysis treatments, 2) phosphorus diet control and 3) the use of phosphorus binders (Shi et al., 2013; Satoh et al., 2009).

Although serum phosphorus is removed during dialysis treatments, dialysis alone is inadequate in assisting hemodialysis patients to obtain and maintain normal serum phosphate levels (Cupisti et al., 2012). As a result of this, complementary methods of achieving prescribed levels of serum phosphate in HD patients include the use of phosphorus binders and phosphorus dietary restrictions. Unfortunately, while studies have demonstrated that this three-pronged method of serum phosphate control (dialysis, diet and the use of binders) is effective in achieving desired serum phosphorus goals, it is estimated that as many as $50 \%$ of HD patients are not adherent to their prescribed diet regimen. In addition, up to $80.4 \%$ of HD patients report not using their phosphate binders, further making them at risk for hypherphosphatemia (Kugler, Maeding \& Russell, 2011). Because of the significant associated risks related to hyperphosphatemia in HD patients, there arises a need to provide an evidenced-based intervention associated with positive outcomes to assist these patients to achieve treatment goals.

Many studies have demonstrated that educational interventions are useful in assisting hemodialysis patients achieve better health outcomes by improving HD adherence to both dietary restriction and the use of phosphate binders (Bayoumi, 2010; Van, Huybrechts, Van \& Elseviers, 2011). Increased knowledge, better understanding of their disease process and active participation in health behaviors, including dietary restrictions, have been suggested as methods to improve HD adherence and phosphorus control (Baraz, Parvardeh, Mohammadi \& Broumand, 2009; Cupisti, et al., 2012; Brogdon 2013; Reddy et al., 2009) 


\section{Literature Review}

Kidney disease is a worldwide phenomenon affecting as many as 6-18\% of people globally (Jha et al., 2013). In the United States, an estimated 26 million individuals have chronic kidney disease and in more than 570,000 of these individuals, CKD has progressed to ESRD (American Society of Nephrology, 2014). Progression to ESRD is especially problematic because ESRD-related deaths rose from 10,478 in1990 to 90,118 in 2009 (NKUDIC, 2009). While the cause of death remains varied among this patient population, cardiovascular events have been singled out as the number one cause of death in patients with ESRD (Shi et al., 2013). In patients with ESRD stages 3 and 4 who must obtain treatment for their failed kidneys, hemodialysis is the most common method of obtaining renal replacement treatment (Idier, Untas, Koleck, Chauveau \& Rascle, 2011). The relationship between hyperphosphatemia in dialysis patients and mortality has been reported by various studies (Kalantar-Zadeh et al., 2010; Sullivan et al., 2009; Baldwin, 2013; Satoh et al, 2009). While studies continue to show that adherence to the hemodialysis treatment regimen prolongs life in ESRD patients, adhering to such treatment regimens continue to be a challenge to patients, their caregivers and healthcare providers (Cupisti, et al., 2012; Nguyen \& Wang, 2012). Adhering to the hemodialysis treatment regimen involves a complex, intertwining balance of many components, including the monitoring of dietary and serum sodium and potassium as well as adherence to medication and treatment regimens. Providing HD patients with tools, such as an effective educational intervention, is necessary to support these patients in adhering to their complex treatment regimen. 
Using the following databases: PubMed (2009-2014), Cumulative Index of Nursing and Allied Health Literature (CINAHL) and Cochrane, studies were obtained that tested the effect of educational interventions on hemodialysis patients with higher than normal phosphorus levels. To obtain the most useful and current data, the search years were limited to five (2009 - 2014), using the following terms individually or in combination: hemodialysis, haemodialysis, phosphate, phosphorus, high phosphorus, hyperphosphatemia, education, educational intervention, adherence, non-adherence, and end-stage renal disease. Study inclusions were English language and full-text.

\section{Phosphorus Binders and Hemodialysis Patients}

Martins et al. (2013) assessed potentially modifiable factors that served as hindrances to phosphorus binder use in HD patients. Using a cross-sectional study, the authors demonstrated that certain factors such as the patient's knowledge and understanding of prescribed medications, their health beliefs and the patients' perception of dialysis staff support for the use of phosphate binders, all played significant roles in phosphate binder adherence levels in hemodialysis patients. The intervention was not only designed to educate the participants on the importance of adhering to the hemodialysis treatment regimen in general but to specifically emphasize the role and importance of phosphorus binder use in HD patients. The findings of the study were very useful since they demonstrated that modifiable factors, such as lack of patient knowledge and understanding of phosphorus binder use, are hindrances to phosphorus binder use in HD patients. However, a limitation of the study is the use of patient self-report to assess patient's adherence in light of Buscher, Hartman, Kallen \& Giordano (2011) findings that self-report is not always reliable. 


\section{Prevailing High Phosphorus Diet}

According to Sullivan et al. (2009), hyperphosphatemia is not only dangerous to patients with ESRD but it is possibly harmful to the general population. In a randomizedcontrolled trial enlisting 279 participants, the researchers concluded that patient education had at least a modest impact on the reduction of phosphorus levels in HD patients. Not only did the serum phosphate level decrease in the intervention group by $1.0 \mathrm{mg} / \mathrm{dL}(\mathrm{P}<$ $.001)$ versus $0.4 \mathrm{mg} / \mathrm{dL}(\mathrm{P}=.02)$ in the control group, but the intervention group was also noted to have significantly higher rates of reading nutrition and ingredients labels. According to Sullivan et al. (2009), paying greater attention to dietary phosphorus found in food additives is significant because of the increasing amounts of phosphorus additives in the diet of people living in the US. One limitation of the research was that only patients from one geographical area were included in the study. One effect of this limitation is that the impact of the intervention may not be generalizable. Also since the effects of the intervention were assessed within a period of three months, the long-term effect of the intervention may be different from those initially observed.

\section{Self-management Improves Phosphorus Level}

Lingerfelt \& Thornton (2011) demonstrated that a one-on-one educational intervention improved knowledge of patients with ESRD in relation to their medical treatment and the self-management of their disease process. The educational intervention consisted of presenting the patients with a handbook and reviewing the contents of the handbook with patients as they received dialysis treatments over the course of four weeks. One defining criteria in the study was that participants were within six-months of 
their initiation of dialysis treatment. Although patients new to dialysis may lack knowledge in relation to their disease processes and treatment regimen, restricting the study to only this group of patients means that the result of the study might not be generalizable to patients who have been on dialysis for periods longer than six months. Also, prior exposures to educational materials before the educational intervention were not assessed, leading to inability to fully assess the effect of the study's intervention.

In a randomized controlled trial, Moattari, Ebrahimi, Sharifi \& Rouzbeh (2012) sought to determine the impact of an empowerment program on self-efficacy, quality of life, as well as clinical and laboratory indicators in HD patients. Using pre and posttests, the study demonstrated that both individual and group empowerment counseling sessions improved self-efficacy and quality of life as well as the patients' blood pressure and interdialytic weight gain. However, with the exception of increased hemoglobin and hematocrit levels in the experimental group, the two groups did not significantly differ in other laboratory findings. Apart from this, the small sample size of 48 participants in a homogenous culture may make the generalization of the study findings problematic.

\section{Nurse-led Educational Intervention and Phosphate Binder Use}

Various studies have demonstrated that nurse-led educational interventions are effective in increasing adherence to treatment regimens in hemodialysis patients. In a nurse-led study by Van, Huybrechts, Van \& Elseviers, (2011), an educational and counseling intervention led to increased use of phosphate binders from $83 \%$ pre intervention to $94 \%$ post intervention. In the same study, participants' knowledge regarding phosphorus binder use increased from 53\% to $75 \%$ on average after the 
intervention, serum phosphate levels also decreased from 4.9 to $4.3 \mathrm{mg} / \mathrm{dL}$ in the intervention group. One limitation of the study was that it relied upon patient report of adherence and this may not always be reliable (Buscher, Hartman, Kallen \& Giordano, 2011). The study used electronic monitoring with devices such as the Medication Event Monitoring System which is expensive and may make the replication of the study less likely. Also, the investigators assumed that phosphate binders were taken each time the box was opened, which might not always be so.

A study by Sandlin Corradini, Bennet \& Ockerby (2013) assessed the impact of a nurse-led educational intervention on the phosphorus binder use by hemodialysis patients. The study demonstrated that such interventions can increase patients' adherence to the use of phosphorus binders, though in the study the participants serum phosphate levels did not change significantly post intervention. A limitation of the study was that while some patients completed the survey on their own, there was potential for bias because other patients obtained the assistance of the nurse in completing the survey.

The effectiveness of a nurse-led educational intervention was also demonstrated by a recent study by Shi et al. (2013) that sought to determine the effect of an educational intervention on the knowledge of phosphorus and the management of hyperphosphatemia in patients with CKD. In that study, the knowledge score of the experimental group increased significantly $(\mathrm{F}=207.44, \mathrm{p}<0.001)$ vs. $(\mathrm{F}=37.98, \mathrm{p}<0.001)$ in the control group post nurse-led educational intervention. There was also a mean improvement of knowledge score of +12.38 points three months post intervention in the experimental group, as compared to those who received standard treatment. These results suggest a nurse-led interventional program is effective in increasing the knowledge base of 
hemodialysis patients in relation to the use of phosphorus binders. However, the study did not demonstrate a statistically significant difference in participants' serum phosphate levels. Also, the small sample size $(n=60)$ and the use of a non-validated survey were limitations of the study.

\section{Other Professionals and Hemodialysis Patients}

Nurses are in a unique position to influence adherence to phosphate binder use since they interact with dialysis patients on a day-to-day basis. However, a collaborative effort combining the expertise of other healthcare providers such as nephrologists, renal dietitians and pharmacists may pay greater dividends in reducing the prevalence of hyperphosphatemia in HD patients. While many nurse-led interventions have demonstrated that educational interventions are effective in lowering phosphorus levels in HD patients, it is important to note that other dialysis staff professionals, such as dietitians and pharmacists, have also provided data that show that patients can achieve lower phosphorus levels after an educational intervention. In a pharmacist-led study by Satoh et al. (2009), the researchers demonstrated that an educational intervention is effective in assisting HD patients to lower their serum phosphate levels and their calcium $\mathrm{x}$ phosphate product. Besides the disadvantages associated with high serum phosphate levels in HD patients, maintaining acceptable calcium x phosphate product levels is also important because abnormal levels of calcium $\mathrm{x}$ phosphate product is associated with increased mortality rates in HD patients (Rostami, Hosseini, Pezeshki, Heidari, \& Einollahi, 2014). In the study by Satoh et al., post educational intervention revealed that patients' serum phosphate levels decreased significantly, especially in patients with serum phosphate levels of $6.0 \mathrm{md} / \mathrm{dL}$ or higher. The authors suggested that educating 
patients on the appropriate use of phosphorus binders has the potential to reduce serum phosphate and the calcium x phosphorus product in HD patients. The authors suggested that providing such an educational intervention should be done before increasing the phosphorus binder dose - a position that was also suggested by Arenas et al., (2010) since the increase in serum phosphate may be due to non-adherence to phosphorus binder use, rather than ineffective medication response. A limitation of the study by Satoh et al. is that the long-term effect of the intervention is unknown.

\section{Individualized Educational Intervention}

Providing an educational intervention on a one-on-one basis to hemodialysis patients has been shown to be effective in achieving dietary restriction goals in hemodialysis patients (Baraz, Parvardeh, Mohammadi \& Brouman, 2009). In a study by Arenas et al. (2010), the researchers demonstrated that nonadherence to medication was a significant problem in hemodialysis patients. In their study of 165 participants, the researchers found that $40 \%$ of the participants were non-adherent to their medication regimen. While the nonadherence rate of phosphate binder use was comparatively lower in this particular group of patients (21\%), Arenas et al. demonstrated that nonadherence itself is associated with excess serum phosphate and potassium levels in hemodialysis patients. An educational intervention designed to improve phosphate adherence in hemodialysis patients should therefore be useful in lowering serum phosphate levels in these group of patients. However, a limitation of the study by Arenas et al. (2010) is that there were no distinct criteria for inclusion or exclusion of study participants. As an example, the educational levels of the participants were not disclosed and according to 
Zheng, Heng, Seng, Ling \& Chang (2011), an individual's educational level impacts the level of self-management habits in patients with chronic disease.

Viewing an educational intervention has also been shown to be an effective method of increasing knowledge about phosphorus control in hemodialysis patients. In a study by Baldwin (2013), participants with high serum phosphorus levels (greater than $5.5 \mathrm{mg} / \mathrm{dL}$ ) who watched an educational video had lower serum phosphate levels after watching the video, although the levels did not significantly decrease further in the randomly selected patients who reviewed the video a second time. The pre and posttest results also demonstrated increased knowledge by the patients after watching the video. An obvious disadvantage of this method of education is that it excludes patients that may be visually or hearing impaired and those with language barriers.

Clinical practice guidelines recommend the serum phosphate of patients in stage 5 kidney disease be maintained between 3.5 and $5.5 \mathrm{mg} / \mathrm{dL}$, while the phosphorus level in patients with stage 3 or 4 should be maintained between 2.7 to $4.6 \mathrm{mg} / \mathrm{dL}$ (National Kidney Foundation Dialysis Outcomes Quality Initiative [K/DOQI], 2003) guidelines. Due to the prevalence of high serum phosphate levels in hemodialysis patients, there is a need to educate the patients on dietary phosphorus restriction.

It is therefore important that serum phosphate levels be carefully monitored in hemodialysis patients to lower this significant health risk. Educating patients on dietary phosphorus control is especially important in light of studies such as Cupisti et al, (2010) which showed that phosphorus knowledge of hemodialysis patients is low in comparison to their knowledge of other nutrients such as protein and potassium. Furthermore various 
studies continue to show that due to the significant consequences of hyperphosphatemia, individualized and ongoing patient education is necessary to decrease this abnormality and its associated high mortality risk in hemodialysis patients (Shi et al., 2013; Satoh et al, 2009; Sandlin, Bennet, Ockerby \& Corradini, 2013, Baldwin, 2013). 


\section{Theoretical Framework}

The Health Promotion Model (HPM) is a middle range theory that emphasizes the active role of the patient in managing health behaviors by modifying the environment (Pender, Murdaugh, \& Parsons, 2011). The theory leans heavily on the social learning theory of Bandura (1997) which postulates the importance of cognitive processes in attaining behavioral change. Self-efficacy (a concept from social learning) is central to the health promotion theory. Providing positive feedback after a display of a targeted behavior by the patient, such as the ability to identify high phosphorus food items, should promote task self-efficacy in the patient according to this model. The HPM depicts cognitive and perceptual factors as major determinants of health-promoting behaviors. Another assumption of the HPM is that self-initiated reconfiguration of personal environmental interactive patterns is essential for behavior change. The theory asserts that family and health care professionals, such as nephrology nurses, are a part of the interpersonal environment that influences individuals throughout their lifespans. An educational intervention by such individuals should yield positive outcomes based upon the HPM. Another assertion of this theory is that people are more likely to participate in health promoting behaviors when such behaviors are modeled, expected or supported by significant others in their lives. One of the assumptions of the HPM is that individuals play an active role in regulating their own behavior. This idea relates to this study, because it is seeking to determine if after teaching the patients, they are able to apply the teachings to actively promote their health. If the theory holds true and the patients can come to the conclusion that they are capable of positively affecting change in their situation, then they are more likely to participate in health-promoting behavior. 
Partnering with the healthcare provider, the patient's dietary knowledge should be increased after teaching.

It has been said that health promotion is the process of enabling people to exert control over the determinants of health to improve their health (World Health Organization, 2009). Therefore, by equipping patients with educational tools with which to exert better control over their health outcome, it is more likely that such healthpromoting behavior would be obtained and maintained over the long run. 


\section{Method}

\section{The Logic Model}

The Logic Model (W.K. Kellogg Foundation, 2004) was utilized to guide the development of the program. The inputs/resources are what were invested: time, money and technology. The outputs/processes are comprised of two components: 'what we do' which included providing an educational intervention through the use of PowerPoint and a pamphlet and; 'who we reach,' made up of participants and the organization's decision makers. In relation to outcomes/impacts, the expected short term changes were increased patient knowledge in relation to phosphorus diet control. Some expected intermediate changes in the participants were a behavioral change as a result of increased awareness of risks associated with hyperphosphatemia, and increased skill in identifying acceptable low phosphorus foods. Long term expectations were enhanced methods of educating hemodialysis patients on dietary phosphorus control, resulting in increased self-efficacy and increased compliance with dietary phosphorus restrictions. 


\section{Program Evaluation - Logic Model}

\begin{tabular}{|c|c|c|c|c|c|}
\hline \multicolumn{2}{|c|}{ Outputs/Processes } & \multirow{2}{*}{$\begin{array}{c}\text { Inputs/ } \\
\text { Resources } \\
\begin{array}{c}\text { What we } \\
\text { invest }\end{array}\end{array}$} & \multicolumn{3}{|c|}{ Outcomes/Impact } \\
\hline What we do & $\begin{array}{l}\text { Who we } \\
\text { reach }\end{array}$ & & Short-Term & Intermediate & Long Term \\
\hline $\begin{array}{l}\text { Provide } \\
\text { Teaching }\end{array}$ & Participants & Time & $\begin{array}{l}\text { Short term } \\
\text { changes we } \\
\text { expect }\end{array}$ & $\begin{array}{l}\text { Intermediate } \\
\text { changes we } \\
\text { expect }\end{array}$ & $\begin{array}{l}\text { Long term } \\
\text { changes we } \\
\text { expect }\end{array}$ \\
\hline $\begin{array}{l}\text { Provide } \\
\text { literature }\end{array}$ & $\begin{array}{l}\text { Decision } \\
\text { makers of } \\
\text { the } \\
\text { organization }\end{array}$ & Money & $\begin{array}{l}\text { Increased } \\
\text { awareness }\end{array}$ & $\begin{array}{l}\text { Behavioral } \\
\text { change }\end{array}$ & $\begin{array}{l}\text { Increase in } \\
\text { patients' self- } \\
\text { efficacy }\end{array}$ \\
\hline $\begin{array}{l}\text { Assess } \\
\text { impact of } \\
\text { program }\end{array}$ & & Technology & Attitude & Action & $\begin{array}{l}\text { Increased } \\
\text { compliance } \\
\text { with dietary and } \\
\text { food restrictions }\end{array}$ \\
\hline Adapted from: & & & Skills & Action & $\begin{array}{l}\text { Change in } \\
\text { organizational } \\
\text { method of } \\
\text { educating } \\
\text { patients or } \\
\text { teaching }\end{array}$ \\
\hline
\end{tabular}

http://www.uwex.edu/ces/pdande/evaluation/pdf/LMfront.pdf

\section{Needs Assessment}

The Centers for Medicare \& Medicaid Services (CMS) issued a rule linking quality of care to payment rates for dialysis centers that provide services for patients with ESRD (CMS, 2015). The quality incentive program was designed to further motivate these facilities to improve the quality of care provided to their patients. Although dialysis companies, such as the one where the program was implemented, provide unparalleled care to their patients, the CMS incentive was considered an added 'push' for dialysis centers to reach predetermined acceptable goals. Monitoring patients' phosphorus levels is one of the measures adopted by CMS in 2014 as an incentive for dialysis facilities to 
improve quality of care and better outcomes for patients with ESRD. The payments facilities receive are dependent on the facility's ability to obtain acceptable scores based on the quality of care the facility provides. It is therefore imperative that dialysis centers achieve these scores to remain viable - a goal that cannot be achieved without assisting their patients to achieve better health outcomes, such as a good control of their phosphorus level. According to the facility administrator (D. Lynch, personal communication, June 30, 2015) many patients at the dialysis center where the program was implemented were unable to achieve and or maintain their phosphorus level within the centers approved acceptable range, necessitating a need for further intervention.

\section{Program Content and Objectives}

The teaching intervention utilized a pre and posttest design. The intervention was provided using a laptop computer and administered individually to each participant. The participants were provided with a take-home brochure (Appendix 3) and a fact sheet (Appendix 4) to reinforce the content of the educational intervention. The content addressed the following learning objectives: 1) Participants will identify examples of foods with phosphorus additives. 2) Participants will be able to identify strategies to control dietary phosphorus intake. 3) Participants will identify some consequences of hyperphosphatemia. Before the educational intervention, a pretest was used to determine the knowledge base of the participants. The intervention started immediately after the pretest. A posttest was administered after the intervention to evaluate the effect of the educational intervention on patients' knowledge of phosphorus, followed by one openended qualitative question (Appendix 5). Both pretest and posttest were in paper and pencil format and consisted of a set of 16 multiple choice questions (Appendix 2), 
adapted from Ford, Pope, Hunt \& Gerald (2004). Improvement in scores between pre and post testing were analyzed.

\section{Purpose}

The purpose of the program was to determine the effect of an educational intervention on hemodialysis patients' knowledge of dietary phosphorus.

\section{Program Implementation}

\section{Design}

The research design for this study was a pre-test, intervention, posttest one-group design. The program examined the impact of an educational intervention, without randomly assigning the patients into different groups. There was a qualitative component to this study. The student developed the content of the intervention including the pamphlet and the qualitative question. The paper and pen pre and posttests were adapted from Ford, Pope, Hunt \& Gerald (2004). The fact sheet was obtained from the National Kidney Disease Education Program ([NKDEP], 2013).

\section{Sample}

A nonprobability convenience sample of 12 patients undergoing hemodialysis in an outpatient dialysis center was recruited. Inclusion criteria were as follows: (a) age greater than 18 years, (b) routinely receiving hemodialysis treatment 3 times/week, (c) well enough to participate based on the clinical nurse manager's judgment. Exclusion criteria were as follows: (a) inability to speak, hear or understand English; (b) pregnant 
patients or patients on peritoneal dialysis; (c) residence in nursing homes (patients have less control on type of food served); (d) patients with a diagnosis of dementia.

\section{Site}

The program development was carried out in a suburban outpatient dialysis center in Weymouth, Massachusetts. The patient population of the center was 129 . The unit was staffed by a team of healthcare providers including nephrologists, registered nurses, and certified patient care technicians, as well as a Medical Director, a Facility Administrator (FA), a Clinical Coordinator, a Social worker and a Registered Dietitian.

\section{Procedures}

The student met with the dialysis center's FA and determined how approval for the project would be provided. A letter of agreement allowing the study to be conducted at the unit was provided by the FA to the student.

In week 1 (recruitment period), the facility identified HD patients that met the inclusion criteria and provided them with recruitment flyers. Potential participants who inquired about the study were directed to the investigator. Consent was obtained from potential participants after the study had been fully explained by the investigator. Participants then completed the demographic questionnaire (Appendix 1).

Immediately before the intervention began (week 2 for Monday, Wednesday and Friday patients, and week 3 for Tuesday, Thursday and Saturday patients) study participants were given a pre-test (Appendix 2). All tests were independently completed except for one participant who requested assistance in reading the questions. Following 
the pre-test, a one-on-one educational intervention was provided by the student investigator to study participants using a PowerPoint presentation on a laptop computer. The patients were also provided with a take-home educational pamphlet (Appendix 3) and fact sheet (Appendix 4) to reinforce the educational information provided. The intervention was provided three times per patient (Monday, Wednesday and Friday or Tuesday, Thursday, Saturday) depending on participants' scheduled treatment times. At the end of the intervention period, study participants completed a paper and pencil posttest (same questions as the pretest) and responded to an open-ended question (appendix 5). The open-ended question was designed to obtain feedback from the participants about barriers and facilitators they encountered in relation to phosphorus control. Both pre and posttests took less than 20 minutes each to complete, and each educational session lasted about 30 minutes.

\section{Ethical Considerations; Institutional Review Board (IRB)}

The study was approved by the Rhode Island College IRB, as well as the clinic site's Administrative Review Board. Patient consents were obtained. To protect the privacy and anonymity of participants, a coding system was utilized for this program rather than the use of personal identifiers. In the coding system, the participants were provided with a fishbowl containing many combinations of four random numbers. Participants anonymously picked one of such numbers and these were used to identify them during the program. Paper records were locked in a cabinet and the laptop utilized for the program was password protected. 


\section{Measurement}

The participants' scores on the pre and posttests were compared to determine changes in knowledge score as a result of the educational intervention. The qualitative questionnaire was administered immediately after the posttest in each group to elicit information about what worked, what did not work and problems patients faced with dietary phosphorous control.

\section{Timeframe}

The program was carried out in four weeks (Appendix 6). Participants were recruited in the first week. In a cohort of patients (Monday, Wednesday and Friday patients), a pretest was given to assess prior knowledge to the content of the educational intervention at the beginning of the intervention in week 2. At the conclusion of the educational intervention in week 2 (in the same group of patients), a post test was given to assess difference in knowledge. In the second set of cohorts (Tuesday, Thursday and Saturday patients), a pretest was administered at the beginning of week 3 to assess participants' prior knowledge of the content of the educational intervention. This was followed by the intervention for this group and a posttest at the conclusion of the educational intervention at the end of week 3. Data analysis took place in week 4.

\section{Organizational/System Factors}

\section{Enabling Factors}

The investigator had worked for the parent dialysis organization for over five years, was familiar with dialysis units and had gained experience working with patients 
on hemodialysis. The investigator also had the support of the staff, the facility administration and organization.

\section{Barriers}

Since the educational intervention took place on a one-to-one basis during dialysis treatment, variability in patient status during treatment meant that the original order of providing the educational intervention to participants was rearranged to accommodate for a sleeping patient on one occasion. Finally, while individualized interventions were more useful to the patient, it was time consuming for the investigator. The student conducted the study on her own time.

\section{Outcome}

At the end of the intervention, there was increased knowledge of dietary phosphorus control in study participants.

\section{Evaluation}

The evaluation of the intervention consisted of a comparison of patients' pre and posttests. The qualitative aspect of the evaluation included participants' responses to an open-ended question about any aid or hindrances to adhering to dietary phosphorus management. Feedback from the nephrologist, FA and registered renal dietitians were used to evaluate the program.

\section{Plan for Dissemination}

The information obtained from this research was made available to the dialysis center where the study was carried out and to faculty and students at Rhode Island 
College. A brochure made for the study may be used to supplement CMS

required monthly education for dialysis patients. The findings of the study support the use of nursing education about dietary phosphorous control and also provide useful information for other disciplines involved in patient care, such as the dietician and the social worker. Improving the knowledge of patients on hemodialysis is an important part of improving quality and length of life for these patients. Publication of the findings of this study will be sought in professional journals such as the Nephrology Nursing Journal. 


\section{Results}

\section{Sample}

A total of 17 patients (13 males and 4 females) were identified as potential participants for the study. Two patients (one male and one female) could not participate due to time constraints. Two females declined participation and one female fell ill before the intervention began. A nonprobability convenience sample of 12 patients undergoing hemodialysis in an outpatient dialysis center was recruited for the study. Inclusion criteria were as follows: (a) age greater than 18 years, (b) routinely receiving hemodialysis treatment three times /week, (c) well enough to participate based on the clinical nurse manager's judgment. Exclusion criteria were as follows: (a) inability to speak, hear or understand English; (b) pregnant patients or patients on peritoneal dialysis; (c) residence in nursing homes (patients have less control on type of food served); (d) patients with a diagnosis of dementia.

All participants were patients undergoing hemodialysis treatment in a town in Massachusetts. Study participants were exclusively White males and the average age was 61.4 years (range $35-78$ years). The highest number of study participants (50\%) was in the 71-80 years age group. Most study participants (91.7\%) had been on dialysis for five years or less. Eight of the participants $(66.7 \%)$ were married, three participants $(25 \%)$ were single and one (8.3\%) was divorced. Five study participants (41.7\%) were retired and four $(33.3 \%)$ were still employed. All study participants attended high school and most $(58.3 \%)$ had some college education. Demographic information is displayed in table 1. 
Table 1: Demographics

\begin{tabular}{|c|l|l|}
\hline Characteristics & Numbers of Participants & Percentage \\
\hline $\begin{array}{l}\text { Gender } \\
\text { Male }\end{array}$ & 12 & \\
\hline Age & 1 & $100 \%$ \\
31-40 & 3 & \\
$41-50$ & 1 & $8.3 \%$ \\
$51-60$ & 1 & $25.0 \%$ \\
$61-70$ & 6 & $8.3 \%$ \\
$71-80$ & 12 & $50 \%$ \\
\hline Race/ethnicity & & \\
White & 3 & $100 \%$ \\
\hline Marital status & 8 & \\
Single & 1 & $25.0 \%$ \\
Married & & $66.7 \%$ \\
Divorced & 2 & $8.3 \%$ \\
\hline Education & 3 & \\
Attended high school & 4 & $16.7 \%$ \\
High School diploma/equivalent \\
Undergraduate degree & 3 & $33.0 \%$ \\
Graduate degree & & $25.0 \%$ \\
\hline Number of years of dialysis & 1 & \\
1 to 5 years & 11 & $8.3 \%$ \\
6 to 10 years & 4 & $91.7 \%$ \\
\hline Work status & 3 & \\
Employed & 5 & $25.3 \%$ \\
Unemployed & & \\
Retired & & \\
\hline
\end{tabular}

Almost all study participants (91.7\%) had an increase in their test scores post intervention with only one study participant (8.3\%) obtaining an identical pre and posttest score as shown below: 
Table 2: Pre and Posttest Scores ( $\mathrm{N}=12)$

\begin{tabular}{|l|l|l|}
\hline Participants & Pretest Score & Post test Score \\
\hline 1 & 12 & 14 \\
\hline 2 & 8 & 9 \\
\hline 3 & 10 & 15 \\
\hline 4 & 9 & 13 \\
\hline 5 & 13 & 16 \\
\hline 6 & 11 & 15 \\
\hline 7 & 10 & 15 \\
\hline 8 & 9 & 15 \\
\hline 9 & 13 & 15 \\
\hline 10 & 12 & 12 \\
\hline 11 & 11 & 13 \\
\hline 12 & 9 & 13 \\
\hline
\end{tabular}

Table 3: Graph illustration of Pre and Post Test Scores

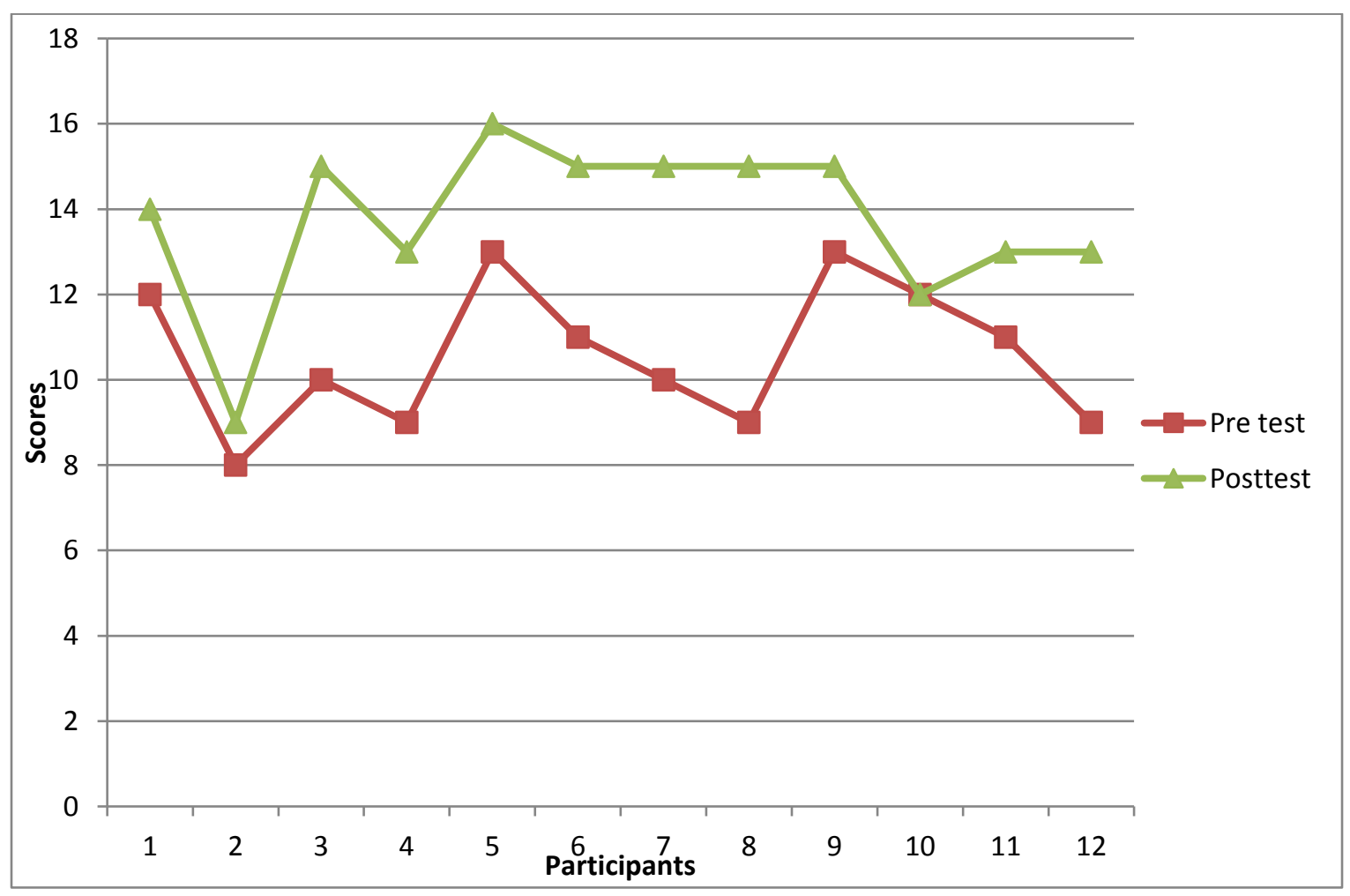




\section{Evaluation of Results}

Demographic analysis was described based on the spread of data. The International Business Machine Statistical Package for Social Sciences [IBM SSPS (Version 24)] was used for statistical analysis. The Shapiro-Wilk test was performed to test for normality in the pre and post test scores. The pretest scores were normally distributed $(\mathrm{SW}[12]=0.93, \mathrm{p}=.41)$ and the post score were not normally distributed $(\mathrm{SW}[12]=.84, \mathrm{p}=.03)$. The Wilcoxon Matched-Pairs test was used to determine the relationship between the pretest and posttest scores. An $\alpha$-level of 0.5 was used with a critical value of 10 (Wilcoxon Signed Ranks table). Calculated W-value is $\mathrm{O}, \mathrm{W}+=66$.

$\mathrm{Z}$ value $=-2.97$. Calculated $\mathrm{W}<\mathrm{W}$ critical, therefore the result is significant at $\mathrm{p}<.05$. The Wilcoxon Matched-Pairs test therefore indicated that there was a significant increase in knowledge post intervention in study participants.

\section{Test Summary}

Table: 4. Wilcoxon Signed Ranks Test

\section{Ranks}

\begin{tabular}{|c|c|c|c|c|}
\hline & & $\mathrm{N}$ & Mean Rank & Sum of Ranks \\
\hline \multirow[t]{4}{*}{ Posttest - Pretest } & Negative Ranks & $0^{\mathrm{a}}$ & .00 & .00 \\
\hline & Positive Ranks & $11^{\mathrm{b}}$ & 6.00 & 66.00 \\
\hline & Ties & $1^{c}$ & & \\
\hline & Total & 12 & & \\
\hline
\end{tabular}
a. Posttest < Pretest
b. Posttest $>$ Pretest
c. Posttest $=$ Pretest 


\section{Table 5: Pretest -Post test}

\begin{tabular}{|l|l|}
\hline $\mathrm{Z}$ & -2.9747 \\
\hline Asymp. Sig. (2-tailed) & .003 \\
\hline
\end{tabular}

The result of the Wilcoxon signed rank test shows there was significant difference between pre and posttest scores, $\mathrm{z}=-2.97, \mathrm{p}<.05$.

\section{Qualitative Responses}

Several themes emerged in response to the prompt 'after the teaching, what enabled you to monitor or hindered you from monitoring your phosphorus?

\section{Hindrances:}

\section{Outings/ Social Gatherings}

While two participants stated they did not have any hindrance to adhering to a low phosphorus diet, the majority of respondents cited eating out, attending social functions and limited food options to choose from as hindrances to following a low phosphorus diet. One participant lamented:

'I feel like I cannot eat anything, everything I like I cannot have. This is a horrible disease I tell you'. (70 year old patient)

Another participant stated: 
'It was my daughter's wedding and my soon to be son-law took us out to eat. It's hard to avoid all those foods and drinks. I had a couple of beers, but I don't drink all the time.' (69 year old patient)

\section{Enablers:}

In relation to what enabled them to adhere to a low-phosphorus diet, all study participants stated that the information provided during the educational intervention has been very helpful to them.

\section{Helpful Information/Increased awareness}

Obtaining helpful information leading to an increased awareness of foods to avoid to lower phosphorus consumption emerged as the most prominent theme in the participants' reason for adhering to a low phosphorus diet. Participants alluded to this in several ways including:

'Knowing what foods and drinks have phosphorus in them, the more information the better' (49 year old patient)

'Ifeel this was very informative and centrally help my choices of eating to keep my level of phosphorus low.' (72 year old patient)

'Information allows for better food/beverage choices and elimination of foods \& beverages currently being consumed'. 'Handout showing certain brand is very good, 'PHOS' is key in selection of dietary food \& beverages'. (69 year old patient)

\section{Reading Food Labels}


Several participants recounted how they were more apt to read food labels since the teaching was done. One participant reported:

'I was looking at my son's sport drink the other day, guess how much phosphorus was in it? $800 \mathrm{mg}$, I couldn't believe it, I'm not touching that any more'. (54 year old patient)

In response to what enabled adherence to a low phosphorus diet, another participant stated:

'Read labels, be aware what is high in phosphorus. I wasn't thinking about what I was eating. I was taking my binders but eating what I want. I think it will be better now, now that I know what to eat and drink.' (73 year old patient)

While another stated:

'What to look for in food labels and food that are high in phosphorus' (72 year old patient).

\section{Support System}

The availability of a support system (either family members or friends) emerged as a positive influence on participants' ability to better manage their phosphorus intake. Participants described how these individuals influenced their food and drink choices by either reading food labels before items are purchased, being knowledgeable of their food restrictions, or supporting them by drinking/eating the same things they are having so the participants did not feel left out. One participant described how he had started making his own iced tea and how his wife has also switched to drinking homemade tea, which was lower in phosphorus than store-bought brands. One participant stated: 
'I appreciate you getting me involved and aware of what is going on. My wife is a good help, she is more aware of it.' (73 year old patient)

Another acknowledged the support of his friend:

'A little help from a friend, watch what you eat and drink.' (54 year old patient)

\section{Study Limitations}

The current study obtained a posttest within one week of providing patient education therefore the long term effects of the intervention are unknown. Also, all participants were White males - this does not provide an adequate representation of patients on dialysis. The small sample size carried out in only one dialysis center also further limits the study. 


\section{Summary and Conclusions}

Hyperphosphatemia is a significant problem in patients with ESRD leading to increased morbidity and mortality risks in this patient population (Petrović, Obrenović, Trbojević-Stanković, Majkić-Singh \& Stojimirović, 2012). While dialysis assists in the removal of toxic substances including excess phosphorus in HD patients, dialysis alone cannot be relied upon to control serum phosphate. Given the limitations of HD, dietary phosphorus control and the proper use of phosphorus binders are important aspects of serum phosphate control in HD patients. However, non-adherence to the treatment regimen is a significant hindrance to achieving outcome goals in HD patients. Since lack of knowledge has been associated with low adherence levels in this patient population, it is imperative that healthcare providers provide effective patient education to support these patients to achieve desired treatment outcomes. As revealed in this study and as supported by others (Ahrari, Moshki, \& Bahrami, 2014), the inclusion of family members and other patient defined supporters in education is more effective than providing education to patients alone. In addition to educating patients about dietary phosphorus control, it is also important to emphasize the proper use of phosphorus binders to obtain and maintain recommended phosphorus levels in ESRD. 


\section{Recommendations and Implications for Advanced Nursing Practice}

Providing patient education is an important part of ensuring that patients have adequate knowledge about their treatment regimen. Family members are recognized as important members of the team involved in the care of patients with chronic diseases (Rosland, \& Piette, 2010). Including friends and family members in educational interventions for individuals on HD may be especially beneficial, because ESRD patients have to abide by a strict dietary regimen, and support from friends and family may be linked to effective self-management and better outcomes in people with chronic diseases (Rosland, Heisler, Janevic, Connell, Langa, Kerr \& Piette, 2013).

The study added to the evidence that a nurse-led educational intervention can increase knowledge in hemodialysis patients. This finding is supported by other studies such as Wells, (2011) and Karavetian \& Ghadder (2013). The educational intervention in this study involved various components including; educating patients on the risks and complications of hyperphosphatemia, providing information on high phosphorus foods and drinks to avoid and examples of low phosphorus foods and drinks that may be consumed, importance of properly taking phosphorus binders, and the provision of colorful handouts to patients. All of these components have been identified by Karavetian, de Vries \& Elzien (2014) as parts of an effective 'formula' for the provision of dietary education to patients on hemodialysis, and may be useful when providing educational interventions for ESRD patients.

Due in part to the limitations of the current study, however, there is a need to implement more research that includes both genders, more age groups, and individuals 
from racially and ethnically diverse populations, to better represent ESRD patients on hemodialysis, making the results more generalizable.

The information obtained from this research was made available to the dialysis center where the study was carried out and to faculty and students at Rhode Island College. A brochure made from the conducted study may be used to supplement CMS required monthly education for dialysis patients. The findings of the study support the use of nursing education about dietary phosphorous control and also provide useful information for other disciplines involved in patient care, such as the dietician and the social worker. Improving the knowledge of patients on hemodialysis is an important part of improving quality and length of life for these patients. Publication of the findings of this study will be sought in professional journals such as the Nephrology Nursing Journal. Improving the knowledge of patients on hemodialysis is an important part of providing care for these patients. Since nurses have access to patients in the course of every treatment, advanced practice registered nurses can train other nurses in the use of evidenced-based methods of providing patient education leading to positive patient outcomes. 


\section{References}

Abe M, Okada K. \& Soma, M. (2013). Mineral metabolic abnormalities and mortality in dialysis patients. Nutrients, 5(3):1002-1023.

Ahrari, S., Moshki, M. \& Bahrami, M. (2014). The relationship between social support and adherence of dietary and fluids restrictions among hemodialysis patients in Iran. Journal of Caring Sciences, 3(1), 11-19.

American Heart Association. (2014). Stroke and high blood pressure. Retrieved from http://www.heart.org/

American Society of Nephrology. (2014). Kidney Health Initiative. Retrieved from http://www.asn-online.org/khi/faq.aspx

Arenas, M. D., Malek, T., Gil, M. T., Moledous, A., Alvarez-Ude, F., \& Reig-Ferrer, A. (2010). Challenge of phosphorus control in hemodialysis patients: a problem of adherence? Journal of Nephrology, 23(5), 525-534.

Baldwin, D. M. (2013). Viewing an educational video can improve phosphorus control in patients on hemodialysis: A pilot study. Nephrology Nursing Journal, 40(5), 437442.

Bandura, A. (1997). Self-efficacy: The exercise of control. New York: W.H. Freeman and Company.

Baraz, S.H., Parvardeh, S., Mohammadi, E. \& Broumand, B. (2009) Dietary and fluid compliance: an educational intervention for patients having haemodialysis. Journal of Advanced Nursing 66(1), 60-68. 
Bayoumi, M. \& El-Fouly, Y. (2010). Effects of teaching programme on quality of life for patients with end-stage renal disease. Journal of Renal Care 36(2), 96-101.

Brogdon, R. (2013). A Self-care educational intervention to improve knowledge of dietary phosphorus control in patients requiring hemodialysis: a pilot study. Nephrology Nursing Journal, 40(4), 313-318, 327.

Buscher, A., Hartman, C., Kallen, M.A. \& Giordano, T.P. (2011). Validity of self-report measures in assessing antiretroviral adherence of newly diagnosed, HAARTnaïve, HIV patients. HIV Clinical Trials, 12(5): 244-254. doi: 10.1310/hct1205244

Centers for Medicare \& Medicaid Services (2015). ESRD Quality Incentive Program. Retrieved from: https://www.cms.gov/Medicare/Quality-Initiatives-PatientAssessment-Instruments/ESRDQIP/index.html

Cupisti, A., Ferretti, V., D'Alessandro, C., Petrone, I., Di, G. A., Meola, M., Panichi, V., ... Capitanini, A. (2012). Nutritional knowledge in hemodialysis patients and nurses: focus on phosphorus. Journal of Renal Nutrition, 22(6), 541-546.

Ford, J.C., Pope, J.F., Hunt, A. E., \& Gerald, B. (2004). The effect of diet education on the laboratory values and knowledge of hemodialysis patients with hyperphosphatemia. Journal of Renal Nutrition, 14, 1, 36-44.

Gonzalez-Parra E., Tuñón, J., Egido J. \& Ortiz, A. (2012). Phosphate: a stealthier killer than previously thought? Cardiovascular Pathology, 21(5):372-381. 
Hruska, K., Choi, E., Memon, I., Davis, T., \& Mathew, S. (2010). Cardiovascular risk in chronic kidney disease (CKD): the CKD-mineral bone disorder (CKD-MBD). Pediatric Nephrology, 25(4), 769-778. doi:10.1007/s00467-009-1337-0

Idier, L., Untas, A., Koleck, M., Chauveau, P. \& Rascle, N. (2011). Assessment and effects of therapeutic patient education for patients in hemodialysis: a systematic review. International Journal of Nursing Studies, 48(12), 1570-1586.

Jha, V., Garcia-Garcia, G., Iseki, K., Li, Z., Naicker, S., Plattner, B., ... \& Yang, C. W. (2013). Chronic kidney disease: global dimension and perspectives. The Lancet, 382(9888), 260-272.

Kalantar-Zadeh K, Gutekunst L, Mehrotra R, Csaba, P.K., Bross, B., Shinaberger, C.S., ... (2010). Understanding sources of dietary phosphorus in the treatment of patients with chronic kidney disease. Clinical Journal of the American Society of Nephrology, 5(3):519-530.

Kugler C, Maeding I, Russell CL. (2011). Non-adherence in patients on chronic hemodialysis: an international comparison study. Journal of Nephrology. 24(3):366-75. doi: 10.5301/JN.2010.5823

Lertdumrongluk, P., Rhee, C.M., Park, J., Lau, W.L., Moradi, H., Jing, J.,.., KalantarZadeh, K. (2013). Journal of Renal Nutrition, 23(6), 411-421, doi:

10.1053/j.jrn.2013.01.018 
Li, H., Jiang, Y. \& Lin, C. (2013). Factors associated with self-management by people undergoing hemodialysis: a descriptive study. International Journal of Nursing Studies, 51(2), 208-216.

Lingerfelt, K.L. \& Thornton, K. (2011). An educational project for patients on hemodialysis to promote self-management behaviors of end stage renal disease education. Nephrology Nursing Journal, 38(6), 483-489.

Martins, M. T., Silva, L., Kraychete, A., Reis, D., Dias, L., Schnitman, G., Oliveira, L., ... Lopes, A. (2013). Potentially modifiable factors associated with non-adherence to phosphate binder use in patients on hemodialysis. BioMedCentral Nephrology, 14(1), 208.

Moattari, M., Ebrahimi, M., Shaifi N. \& Rouzbeh, J. (2012). The effect of empowerment on the self-efficacy, quality of life and clinical and laboratory indicators of patients treated with hemodialysis: a randomized controlled trial. Health and Quality of Life Outcomes, 10(1), 1-10.

Mizobuchi, M., Towler, D., \& Slatopolsky, E. (2009). Vascular calcification: The killer of patients with chronic kidney disease. Journal of American Society of Nephrology, 20(7), 1453-1464. doi: 10.1681/ASN.2008070692

National Kidney and Urologic Diseases Information Clearinghouse. (2012). Kidney Disease Statistics for the United States. Retrieved fromhttp://kidney.niddk.nih.gov/kudiseases/pubs/kustats/ 
National Kidney Foundation. (2003). K/DOQI clinical practice guidelines for bone metabolism and disease. American Journal of Kidney Disease, 42(4, Suppl. 3), S1-S202. Retrieved from http://www.kidney.org/professionals/kdoqi/guidelines_bone/pdf/boneguidelines.p df

Nguyen, T. V. \& Wang, A. (2012). Hyperphosphatemia: consequences and management strategies. Journal for Nurse Practitioners, 8 (1), 5660.doi:10.1016/j.nurpra.2011.05.007

Petrović, D., Obrenović, R., Trbojević-Stanković, J., Majkić-Singh, N., \& Stojimirović, B. (2012). Hyperphosphatemia-the risk factor for adverse outcome in maintenance hemodialysis patients. Journal of Medical Biochemistry, 31(3), 239245.

Pender, N., Murdaugh, C.L. \& Parsons, M.A. (2011). Health Promotion in Nursing Practice (6th Edition). Boston, MA: Pearson.

Reddy, V., Symes, F., Sethi, N., Scally, A. J., Scott, J., Mumtaz, R., \& Stoves, J. (2009). Dietitian-led education program to improve phosphate control in a single-center hemodialysis population. Journal of Renal Nutrition, 19(4), 314-320.

Rosland, A.-M., \& Piette, J. D. (2010). Emerging Models for Mobilizing Family Support for Chronic Disease Management: A Structured Review. Chronic Illness, 6(1), 721. 
Rosland, A. M., Heisler, M., Janevic, M. R., Connell, C. M., Langa, K. M., Kerr, E. A., \& Piette, J. D. (2013). Current and potential support for chronic disease management in the United States: the perspective of family and friends of chronically ill adults. Families, Systems, \& Health, 31(2), 119.

Rostami, Z., Hosseini, M. S., Pezeshki, M. L., Heidari, F., \& Einollahi, B. (2014). Bone mineral metabolism and subsequent hospitalization with poor quality of life in dialysis patients. Nephro-urology Monthly, 6(1).

Sandlin, K., Corradini, A.-M., Bennett, P. N., \& Ockerby, C. (2013). The impact of nurse-led education on haemodialysis patients' phosphate binder medication adherence. Journal of Renal Care, 39(1), 12-18.

Satoh, M., Koizumi, A., Izumi, S., Kugoh, Y., Kiriyama, E., Oguma, E., ... Kadowaki, D. (2009). Improvement of hyperphosphatemia following patient education. The Journal of Pharmacy Technology, 25(1), 3-9.

Shi, Y.-X., Fan, X.-Y., Han, H.-J., Wu, Q.-X., Di, H.-J., Hou, Y.-H., \& Zhao, Y. (2013). Effectiveness of a nurse-led intensive educational programme on chronic kidney failure patients with hyperphosphataemia: randomised controlled trial. Journal of Clinical Nursing, 22, 1189-1197. doi:10.1111/jocn.12159

Sinha, A., \& Prasad, N. (2014). Dietary management of hyperphosphatemia in chronic kidney disease. Clinical Queries: Nephrology, 3(1), 38-45.

Sullivan, C., Sayre, S. S., Leon, J. B., Machekano, R., Love, T. E., Porter, D., Marbury, M., ... Sehgal, A. R. (2009). Effect of food additives on hyperphosphatemia 
among patients with end-stage renal disease: a randomized controlled trial. Journal of the American Medical Association, 301(6), 629-35.

Tedla, F.M., Brar, A., Browne, R., and Brown, C. (2011). Hypertension in chronic kidney disease: navigating the evidence. International Journal of Hypertension. doi:10.4061/2011/132405

United States Census Bureau (2010). American Fact Finder. Retrieved from: http://factfinder.census.gov/faces/tableservices/jsf/pages/productview.xhtml?src= bkmk

University of Wisconsin Extension- Cooperative Extension (n.d -a). Program Development and Evaluation. Retrieved from http://www.uwex.edu/ces/pdande/evaluation/index.html

Valente, S. (2003). Critical analysis of research papers. Journal of Nurses in Staff Development, 19(3), 130-142.

Van, C.Y., Huybrechts, S.A., Van, R.B. \& Elseviers, M.M. (2011). Nurse-led education and counselling to enhance adherence to phosphate binders. Journal of Clinical Nursing, 21(9-10), 1304-1313. doi:10.1111/j.1365-2702.2011.03967.x

W.K. Kellogg Foundation. (2004). Logic Model Development Guide. [Guideline Model]. Retrieved from W.K. Kellogg Foundation website: http://www.wkkf.org World Health Organization. (2009). Milestones in Health Promotion Statements from Global Conferences. Retrieved from 
http://www.who.int/healthpromotion/Milestones_Health_Promotion_05022010.p df

Zheng, K. S., Heng, K. Y., Seng, B., Ling, H. H. M., \& Chang, J. Y. (2011). Assessing attitudes of patients towards chronic disease self-management in Singapore. Archives of Pharmacy Practice, 2(1). 


\section{Appendices}

\section{Appendix 1: Demographic Questionnaire:}

1. Gender

2. Age
a. Less than 20
b. $31-40$
c. $41-50$
d. $51-60$
e. $61-70$
f. $71-80$
g. More than 80

3. Race/ethnicity
a. American Indian and Alaskan Native
b. Black/ African American
c. Asian
d. Hispanic/Latino
e. Native Hawaiian and Other Pacific Islander
f. White

4. Marital status
a. Single
b. Married
c. Divorced
d. Widowed

5. What is the highest educational level you obtained?
a. Less than high school
b. Attended or completed high school
d. Attended or completed college 
f. Attempted or completed advanced degree

6. Number of years on dialysis
a. Less than 5 years
b. 6 to 10 years
c. $\quad 11$ to 5 years
d. More than 15 years

7. Work status
a. Employed
b. Unemployed
c. Retired 


\section{Appendix 2}

\section{Dietary Questions}

1. Good phosphorus control depends on:
a. Dialysis
b. Diet
c. Taking a phosphorus binder with meals
d. All of the above

2. Which of the following may happen when phosphorus levels are too high?
a. Itching
b. Dizziness
c. Irregular Heartbeat
d. Cramping

3. What happens when your phosphorus levels are high?
a. Calcium in your blood will get low
b. Calcium is taken out of your bones
c. Your bones may become weak
d. All of the above

4. Which of the following is high in phosphorus?
a. Whole milk
b. $2 \%$ milk
c. Skim milk
d. All of the above

5. When should you take your binder? 

a. Between meals
b. $8 \mathrm{am}, 12 \mathrm{pm}$, and $6 \mathrm{pm}$
c. With all meals and snacks
d. Before bedtime

6. Which of the following foods is low in phosphorus?
a. Cheese
b. Nuts
c. Potatoes
d. Chocolate

7. What is the desired level for phosphorus for dialysis patients?
a. Between 1.0 and 2.5
b. Between 3.0 and 5.5
c. Between 6.0 and 8.0
d. Between 7.0 and 8.5

8. How much phosphorus should you eat in foods in one day?
a. $200-400 \mathrm{mg}$
b. $400-600 \mathrm{mg}$
c. $800-1000 \mathrm{mg}$
d. $300 \mathrm{mg}$

9. Which of the following problems can develop if the amount of phosphorus in your blood is increased?
a. Liver disease
b. Bone disease 
c. Heart disease

d. B \& C

10. Why should you cut back your dietary intake of phosphorus?

a. There is no reason to cut back dietary intake of phosphorus.

b. Because your kidneys cannot properly clear phosphorus from your body.

c. Because your liver cannot properly clear phosphorus from your body.

d. You should increase your intake of phosphorus.

11. Which of the following foods contains large amounts of phosphorus?

a. Strawberries, blueberries and oranges.

b. Cheese, nuts and most cola beverages.

c. Breads, pasta, and rice.

d. Green beans, eggplant and carrots

12. What are phosphate binders?

a. Medications that decrease the level of potassium in your body.

b. Medications that increase the level of magnesium in your body.

c. Medication that decrease the level of phosphorus in your body.

d. Medications that decrease the level of calcium in your body.

13. Complete the statement: "Phosphate binders work by..."

a. Preventing potassium from entering your body in the stomach.

b. Allowing phosphorus to enter the body in the stomach.

c. Preventing calcium from entering your body in the stomach.

d. Preventing phosphorus from entering your body in the stomach.

14. Which of the following is true for you? 

a. I am not sure which of my medications is a phosphorus binder
b. I know which of my medications is a phosphorus binder
c. I am not on a phosphorus binder
d. I am not sure what a phosphorus binder does

15. Which of the following statements are correct?
a. It is important to read food labels.
b. Sometimes phosphorus is added to food to make it taste better.
c. Sometimes phosphorus is added to food to make it last longer.
d. All of the above are correct

16. Which of the following foods are high in phosphorus?
a. Apples
b. Watermelon
c. Peanut butter
d. Peaches 
Appendix 3

\section{Phosphorus Pamphlet}

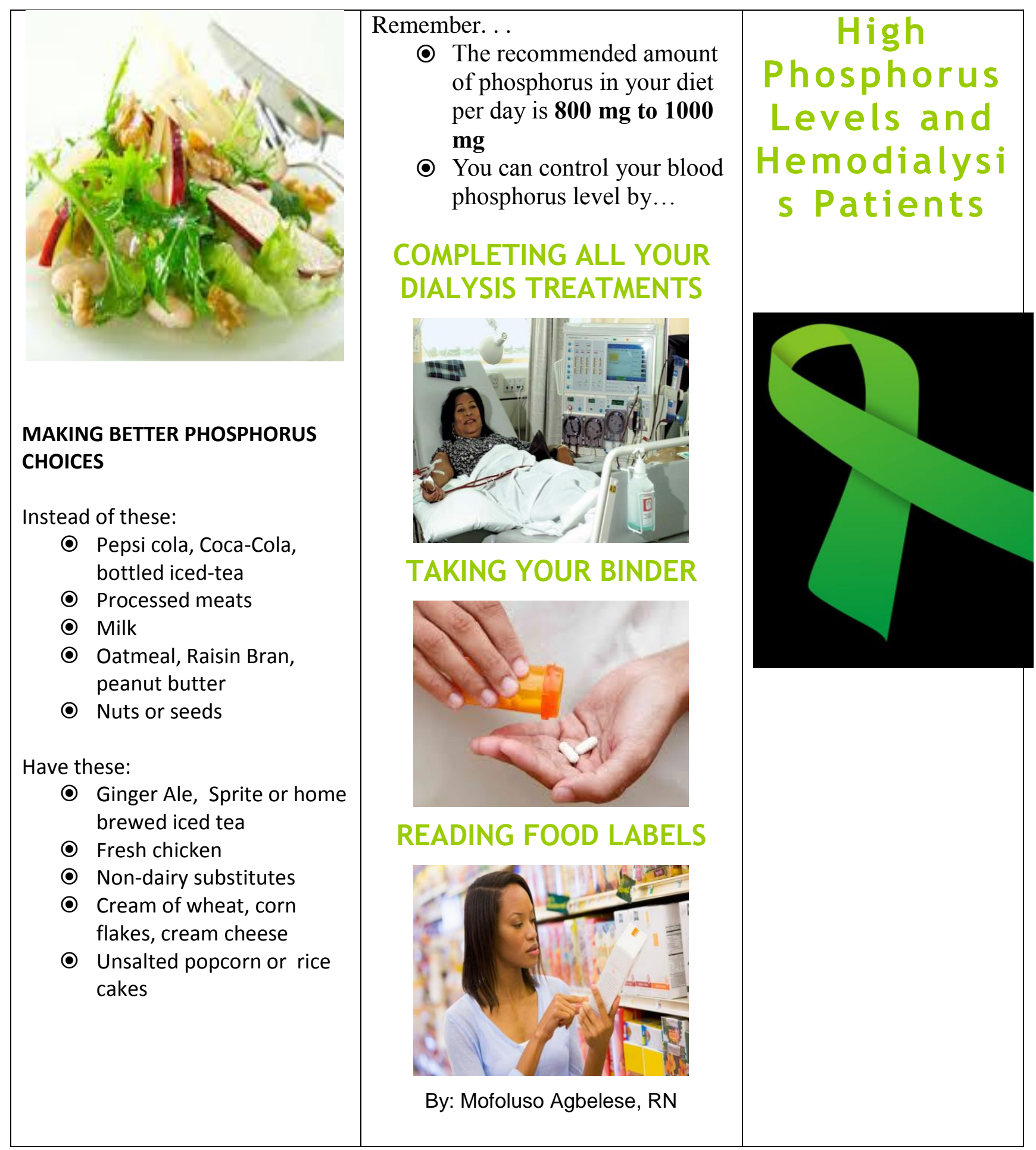




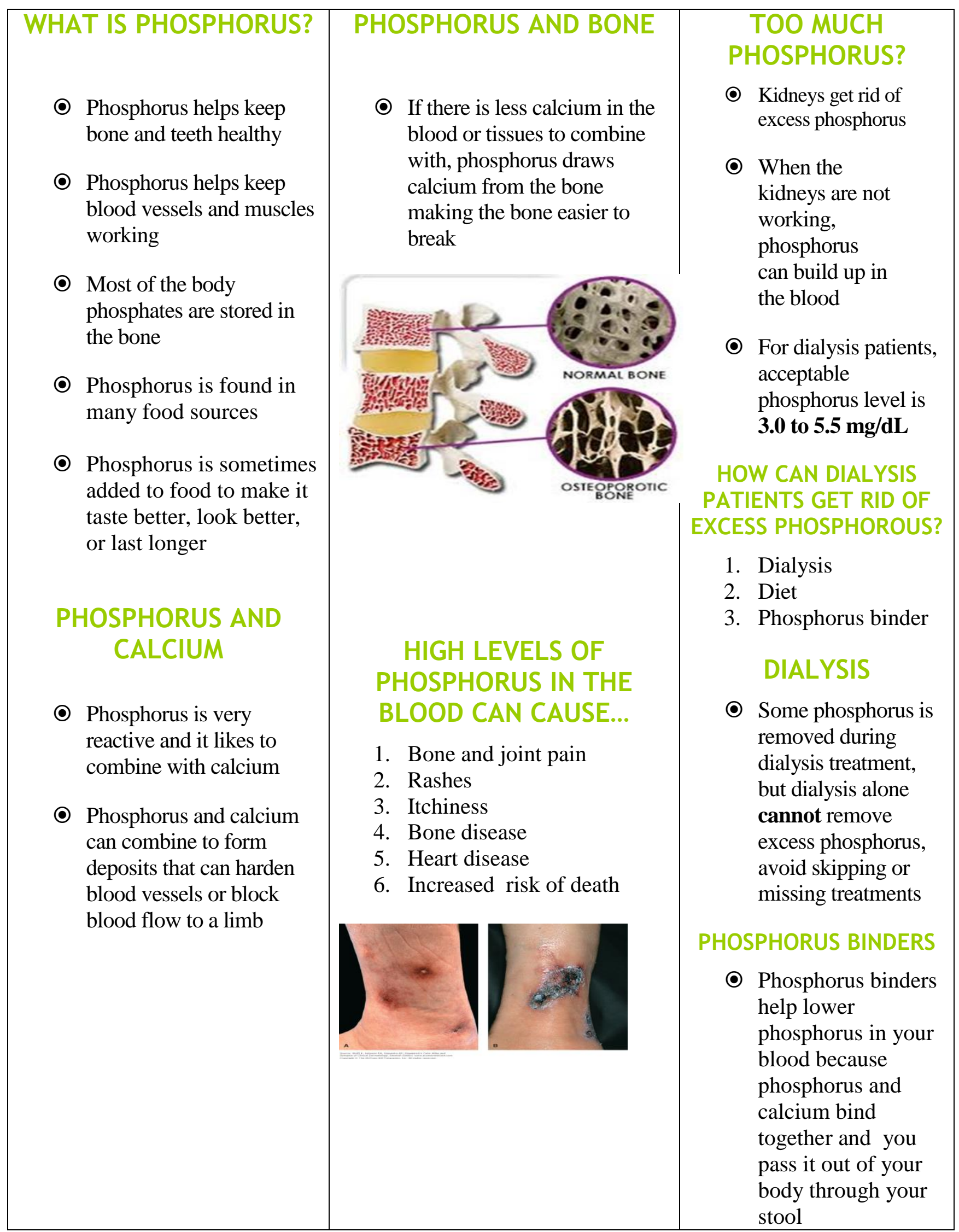


Appendix 4

Fact Sheet

http://www.niddk.nih.gov/health-information/health-communicationprograms/nkdep/a-z/nutrition-phosphorus/Documents/nutrition-phosphorus508.pdf 


\section{Appendix 5 \\ Qualitative Question}

After the teaching, what enabled you to monitor or hindered you from monitoring your phosphorus? 